\title{
Proceeding
}

Supplementary Issue: Rio 2016 Olympic Games Second Anniversary Special Edition. Olympic Studies Forum, 2-3 October 2018.

Federal University of Espirito Santo, (Vitória - Espirito Santo), Brazil

\section{Among identities, claims and resignifications: Memories of the Afro-Brazilian protagonism in the Olympic Sport by Soraia André}

\author{
NEILTON FERREIRA JUNIOR ${ }^{1}$, KATIA RUBIO² $^{2}$ \\ ${ }^{1}$ School of Physical Education and Sport, University of São Paulo (EEFE), São Paulo, Brazil \\ 2Olympic Studies Center, University of São Paulo, São Paulo, Brazil
}

\begin{abstract}
This research investigates and analyzes the trajectory of the Afro-Brazilian Olympic athlete Soraia André , identifying through her memories, narratives and reflections the way in which she constructed and re-signified her identities during her process of insertion, participation and career transition in the sport. The theoretical and methodological bases of this analysis are inscribed in the field of postcolonial and Afrocentric thinking, through which a reflection and writing centred on the protagonism and agency undertaken by the person in focus is proposed. The biographical narrative comprises the main component of this approach that, within its limits, allows to observe the intersectionalities of gender, race and class that structure the relations of power and counterpower and how the cultural identities are articulated. Within this process stands out the athlete Soraia André, whose narrative retrieves in rich detail the complex paths taken by black women in Brazil to reach the Olympic condition and make sport their platform of emancipation. Keywords: Black female athletes; Biographical narratives; Racism.
\end{abstract}

\section{Cite this article as:}

Ferreira Jr., N., \& Rubio, K. (2019). Among identities, claims and resignifications: Memories of the AfroBrazilian protagonism in the Olympic Sport by Soraia André (in Portuguese). Journal of Human Sport and Exercise, 14(3proc), S301-S315. doi:https://doi.org/10.14198/ihse.2019.14.Proc3.03

Corresponding author. Escola de Educação Física e Esporte. Universidade de São Paulo, São Paulo - SP, Brazil.

E-mail: neilton.junior@usp.br

Supplementary Issue: Rio 2016 Olympic Games Second Anniversary Special Edition. Olympic Studies Forum, 2-3 October 2018. Federal University of Espírito Santo, (Vitória - Espírito Santo), Brazil.

JOURNAL OF HUMAN SPORT \& EXERCISE ISSN 1988-5202

(c) Faculty of Education. University of Alicante

doi:10.14198/jhse.2019.14.Proc3.03 


\section{INTRODUÇÃO}

A despeito de sua importância para 0 avanço do conhecimento sobre as dinâmicas históricas e socioculturais, as epistemologias ocidentais, na sua pretensão universalizante, têm se mostrado insuficientes diante da necessidade de compreensão dos saberes que se constituem fora do seu campo de visão. Em outras palavras, porque mais interessadas nas macro-análises, as chamadas ciências humanas modernas tendem subestimar as leituras centradas no papel e importância dos indivíduos dentro do processo histórico (Nascimento, 2009; Farias, 2011). No presente século, entretanto, observa-se uma crescente influência não só das chamadas "abordagens periféricas" e pós-coloniais sobre a prática historiográfica e a crítica social, mas das análises mais centradas nas memórias individuais e coletivas dos sujeitos da história.

Mesma atenção tem sido dirigida à trajetória dos protagonistas esportivos brasileiros das mais diferentes modalidades e épocas, dentre os quais se destaca a experiência singular dos atletas afro-brasileiros (Rubio, 2014; Ferreira Junior, 2017). Mais que oportuno, esse movimento se dá no preciso momento em que, conforme Mbembe (2017, p. 09) analisa, os olhos do mundo se voltam para nós, "e em que a Europa deixa de ser 0 centro de gravidade do mundo", muito embora a "vontade de medir as implicações e as consequências dessas reviravoltas dá ainda os primeiros passos".

Esse "nós", diz respeito não só à África geográfica, mas à experiência dos africanos e de seus descendentes diaspóricos no mundo (Gilroy, 2007). Mais do que uma dispersão, esta experiência representa, conforme se analisará, uma constante relação de tensão, negociação, criação, descentralização, contestação e ressignificação das identidades culturais em relação às identidades culturais que, persistentemente, se pressupõem hegemônicas (Hall, 2003).

Complexidade e irredutibilidade são os termos mais adequados para expressar os desdobramentos e significados desse processo, cuja característica principal pode ser resumida com o termo hibridização (Hall, 2003; Gilroy, 2007). O que não significa necessariamente que os desdobramentos culturais e psicossociais que os séculos de violência colonial produziram (racismo, classismo, misoginismo e xenofobia) tenham deixado de se reproduzir nos mais diferentes campos sociais: à exemplo do contexto esportivo, onde cada vez mais se assiste demonstrações contundentes de que o ódio ao Outro está longe de ser um problema superado. Fato é que as tentativas de superação desse problema têm esbarrado em questões que põem em causa a própria base filosófica que fundamenta o esporte e o multiculturalismo modernos, cuja raiz iluminista - conforme sugere o pensamento pós-colonial - parece ter se esgotado enquanto alternativa civilizatória.

Os movimentos feministas, anti-coloniais e pelos direitos civis ao longo de todo o século XX estabeleceram um novo marco para as relações sócio-institucionais, atenuando a segregação das mulheres e dos negros, chamando a atenção para o problema da invisibilidade a que ambos estavam submetidos e para a necessidade do fomento a sua representatividade política, o que só poderia ser realizado a partir da crítica aos cânones e da valorização dos saberes produzidos pelos próprios excluídos e condenados da terra (Dussel, 1977; Hall, 2003; Fanon, 2008; Gilroy, 2007).

No mesmo sentido, a presente pesquisa busca ancorar-se à crítica pós-colonial e diaspórica, bem como àqueles que de alguma forma evocam em suas práticas reflexivas a necessidade de um olhar centrado nos saberes, memórias e vozes dos sujeitos da história. Longe de querer reduzir as diferentes correntes que constitui o campo de pensamento pós-colonial e diaspórico, este trabalho busca na vertente Afrocentrada 
os elementos constitutivos de sua análise (Nascimento, 2009), assumindo naturalmente os riscos de tal escolha. Pois conforme observam Nascimento (2003), Domingues (2009) e Rubio (2014), embora o tema da memória e do protagonismo histórico das camadas excluídas tem progressivamente assumido posição de destaque no interior das ciências humanas, são muitas as questões que sua prática científica deixa pelo caminho.

As histórias individuais compreendem um dos principais elementos da abordagem micro-analítica, pois é na sua complexidade constitutiva que se revela toda sorte de intersecções, contradições, tensões, relações de poder e contrapoder mediadas, interpretadas e ressignificadas pelos sujeitos históricos que, por meio da memória e da linguagem, tecem um panorama particular sobre uma história que, dentro dos seus limites, trata da experiência de uma coletividade (Farias, 2011; Rubio, 2014). Durante quase todo o século passado, este cenário foi ocupado pelas grandes narrativas nacionalistas de protagonismo político e institucional burguês, bem como por um positivismo histórico-científico notoriamente avesso à cultura popular e à própria emancipação das mulheres e afrodescendentes (Azevedo, 1987; Hall, 2003).

No Brasil, o caráter formal da abolição da escravatura, comumente interpretado como a história da emancipação negra no país, é um dentre os muitos exemplos da manutenção de uma história sem rosto e identidade feminina e negra. Sub-representação que vigora até os dias de hoje, porém, não sem oposição, à exemplo do esforço relativamente recente que estudiosos das mais diferentes áreas têm dirigido não só à recuperação da história dos movimentos organizados, mas da trajetória daqueles à própria maneira se mobilizaram em nome de semelhante e distintas urgências emancipatórias (Nascimento, 2003; Goellner, 2007; Domingues, 2009). Diante de um cenário em que persiste a recusa do Outro enquanto sujeito e autor da própria história, é natural que estes corpos e suas contra-narrativas desencadeiem tensões, uma vez que disputam espaços até então dominados pela oficialidade institucional, patriarcal e monocromática da ciência e historiografia europeia, cuja superação é, segundo Dussel (1977), tarefa urgente da pesquisa que se propõe pensar os excluídos.

A investigação e análise do protagonismo histórico das mulheres negras tem por objetivo devolver a elas não apenas a parte que lhes cabe nos processos sociais, mas revelar a insubordinação e irredutibilidade constitutivas de suas histórias, experiências e identidades.

\section{Protagonismo Afro-Brasileiro}

Em revisão de literatura, Domingos (2009) analisou estudos relacionados ao protagonismo negro no período pós-abolição, identificando um crescente interesse por parte de estudiosos dos mais diferentes campos das ciências humanas nas trajetórias individuais e coletivas da gente afro-brasileira. São pesquisas que apesar dos problemas de ordem teórico-metodológica que apresentam, conforma sinaliza o autor, têm contribuído sobremaneira para a compreensão da importância dos sujeitos no e para os processos históricos e sociais. Esta "revalorização do sujeito na história e a ênfase nas suas experiências individuais", conforme identifica Farias (2011, p. 913), não só reacendeu "o debate em torno da subjetividade enquanto objeto do conhecimento científico", como fez da história oral um dos principais mecanismos através do qual as grandes narrativas da história e dos próprios fenômenos socioculturais puderam ser reinterpretadas. A narrativa oral, conforme prossegue a autora, possui um duplo caráter. Ao mesmo tempo que compreende uma forma de traduzir experiências particulares e conjunturas sociais, constitui-se como via de acesso às identidades, às formas como o sujeito dá sentido ao mundo e à própria presença no mundo.

Por protagonismo afro-brasileiro pós-abolição compreende-se toda recuperação histórica e análise da participação e inserção dos negros na sociedade e cultura a partir da abolição da escravatura. Em oposição 
ao branqueamento e positividade a que são submetidos os processos históricos nacionais, busca-se nesse recorte histórico específico conhecer e descrever como esses sujeitos preservam, reconstroem e ressignificam suas identidades culturais, e como vivenciam as transformações sociais que atravessam suas trajetórias. Há não muito tempo, conforme argumenta Domingues (2009, p. 218), a narrativa historiográfica brasileira ancorou-se à ideia de que após a abolição da escravatura os afro-brasileiros foram deixados à margem tanto do mundo do trabalho quanto da política institucionalizada e educação formal. Despossuídos de qualificação técnica, cultural e renda, não podiam competir com os brancos, obedecendo assim ao destino que o pessimismo racial lhes havia reservado, o de "párias, em estado de desajustamento e anomia social".

Que os afro-brasileiros passaram por uma série de mazelas resultantes dos mais diversos e profundos desdobramentos psicossociais e político-econômicos do colonialismo, não resta dúvida (Fernandes, 1972). Entretanto, suas trajetórias de vida não são lineares, inertes, tampouco passíveis de padronização. Segundo Domingues (2009, p. 218), a presença e participação dos afro-brasileiros na sociedade brasileira, especialmente a partir do pós-abolição, compreende aquilo que se tem evocado como uma antologia ${ }^{1}$ de histórias, plenas de "contradições, ambiguidades, ambivalências e experiências multifacetadas", as quais aumentam em complexidade não só as relações de exclusão, violência, subalternização e alienação, sinalizando para as expressões de resistência, organização, subversão e autoafirmação de sujeitos em busca de sua emancipação.

Mas embora a trajetória dos afro-brasileiros no pós-abolição seja tema de fundamental importância à análise e compreensão crítica do Brasil contemporâneo, esse campo de pesquisa encontra-se ainda em sua fase inicial de desenvolvimento. Até pouco tempo submetidos ao formalismo, reducionismo e positivismo metodológico de sociólogos, antropólogos e cronistas, os afro-brasileiros dificilmente escaparam à condição coadjuvante e às estereotipias (Domingues, 2009). E não raros são os estudos que persistem em abordar 0 referido grupo como uma espécie de massa inerte e inaudita, passível das mais variadas formatações, determinações externas e destinos (Mbembe, 2017). Dentre as implicações desse tipo de historiografia destaca-se a manutenção da ideia de que a emancipação e inserção social dos afro-brasileiros se deu ou se dá sem reivindicação e luta, resumindo-se a concessões por parte das classes dominantes e a arranjos político-institucionais verticalizados.

Por sua vez, a abordagem crítica e protagonista sobre o grupo em destaque concentra-se nos sentidos e significados que os próprios indivíduos atribuem às suas ações, bem como nas suas realizações coletivas. Entende a trajetória afro-brasileira como um processo "cheio de nuances, com avanços e recuos estratégicos" (Miller, 1999, apud, Domingues, 2009, p. 222), próprio das tensões sociais que implicam o ser negro em um mundo idealizado e dominado pelos brancos (Fernandes, 1972), bem como o ser atleta negro em esportes de homens brancos (Wiggins, 2014).

\section{Protagonismo negro no esporte}

Revisitar estudos relacionados à trajetória afro-brasileira no esporte é se deparar com temas como "participação", "inclusão", "representações", "violência racial" e concluir que a despeito do nome negro acompanhar os títulos de tais obras, muito pouco é dito sobre o negro em si; tampouco lhe é permitido narrar a si mesmo, de maneira que suas memórias, reflexões e visões de mundo participem do processo de construção do conhecimento. Quem é e o que é ser negro e atleta negro no Brasil, ou, parafraseando Fanon

\footnotetext{
${ }^{1}$ Coleção de textos escritos, em prosa ou verso, normalmente por autores variados, sendo organizada tendo em conta determinada época, autoria, tema etc.; coletânea. Dicionário Online - https://www.dicio.com.br/antologia/
} 
(2008)2 , o que quer o negro no esporte, são perguntas que acabam ficando em último plano, muito embora tratem especificamente das razões que mobilizam o sujeito à prática esportiva e o fazem permanecer, a despeito das condições e situações desfavoráveis que enfrenta pelo caminho.

Sabe-se, porém, inclusive com riqueza de informações, que os afro-brasileiros passaram a fazer parte do esporte institucionalizado no início do século XX, período em que os clubes de imigrantes europeus começaram a integrá-los às suas equipes de futebol e atletismo. Longe de representar uma "superação crítica" do pessimismo e discriminação racial então vigentes, os primeiros anos desse processo registram histórias de intensa oposição por parte da burguesia, que para além do preconceito racial entendia que a integração dos negros retiraria do esporte o seu "caráter nobre" (Rigo, 1996; Soares, 1999; Santos, 2000; Rodrigues Filho, 2003; Abrahão \& Soares, 2012; Freitas Junior \& Ribeiro, 2012; Oglesby, 2017). 0 que pouco se discute sobre este processo é se a inserção dos referidos atletas nos clubes e ligas tradicionais pode ser resumida à concessões e arranjos institucionais.

A crescente presença dos negros, mestiços e brancos pobres nos clubes e ligas da burguesia a partir dos anos 1920 sugere uma outra narrativa, mais relacionada à um movimento que se constituiu de fora para dentro. Em outras palavras, não teria sido a apropriação da prática esportiva pelas classes trabalhadoras, bem como suas organizações independentes, os fatores mais relevantes e determinantes desse processo?

Teriam os negros e mestiços à época qualquer chance de acesso às divisões oficiais se não fossem previamente capacitados? E uma vez inseridos em um ambiente reconhecidamente hostil a sua presença, como conviveram, sofreram e lidaram com tais hostilidades?

Jesus (1999) identificou que a crescente popularização do futebol em Porto Alegre não escapou à mira da ideologia racista que, em larga medida, estruturava o projeto de "modernidade" empreendido por parte da burguesia no início do século passado. Condição que não oferecia outra alternativa aos negros senão a criação de uma liga paralela, a qual mais tarde seria, pejorativamente, classificada pela imprensa local como a "Liga da Canela Preta". Fundada por volta dos anos 1910, a Liga abria sua temporada de jogos simbolicamente no dia 13 de Maio e contava com a participação de várias equipes. A despeito das necessidades e especificidade investigativa que demandam os casos de protagonismo afro-brasileiro na cultura do futebol, faz-se igualmente necessário o desenvolvimento de pesquisas sobre a trajetória e protagonismo afro-brasileiro em outras modalidades esportivas, de forma que outras narrativas contribuam com a ampliação do fenômeno histórico em foco (Domingues, 2009; Abrahão \& Soares, 2012). Buscando corresponder a esta recomendação, a presente pesquisa constrói sua análise à luz de uma abordagem afrocentrada sobre a trajetória de uma atleta afro-brasileira, a judoca olímpica Soraia André.

\section{CONSIDERAÇÕES METODOLÓGICAS}

O pensamento afrocentrado parte do princípio de que toda observação e análise sobre a presença do negro no mundo deve estar pautada nos desdobramentos psicossociais, econômicos e históricos de sua africanidade e diáspora. Refere-se a uma prática e perspectiva teórica que percebe os africanos e seus descendentes como sujeitos históricos ou, mais precisamente, como "agentes de fenômenos atuando sobre

\footnotetext{
2 Parafraseamos e transferimos para o contexto da presente reflexão uma provocação que Frantz Fanon, faz na obra Pele negra, máscaras branca, ao defender, sob pena do ressentimento dos seus irmãos de cor, "que o negro não é um homem". No interior do substantivo negro, o filósofo entender haver uma espécie de "zona de não-ser, uma região extraordinariamente estéril e árida, uma rampa essencialmente despojada, onde um autêntico ressurgimento pode acontecer". Fanon, F. Pele negra, máscaras brancas. Salvador: EDUFBA, p. 26, 2008.
} 
sua própria imagem cultural e de acordo com seus próprios interesses humanos" (Asante, 2009, p. 93). Indica precisamente uma questão de localização e relocalização, partindo do princípio de que África, africanos e afrodescendentes foram - como ainda têm sido - deixados à margem do mundo e da história em virtude de uma hegemonia cultural e discursiva que insiste apresentá-los segundo uma visão europeia do que seja o mundo, a história, o homem, a razão. "Quer se trate de economia, quer se trate de história, política, geografia ou arte, os africanos" (juntamente como outros povos não-branco-europeus) foram colocados à margem daquilo que se convencionou designar por "real". E é em função de tal descentralização que o pensamento afrocentrado advoga uma redefinição radical de conceitos, bem como uma reorientação do pensar e do fazer político, historiográfico, científico e filosófico capaz de conferir maior centralidade à África e à diáspora africana (Asante, 2009, p. 93).

O método afrocentrado procura destacar do universo que é o sujeito a sua agência, ou seja, sua capacidade e formas de interferência no mundo, autonomia, busca dos próprios interesses, desejos, necessidades. Em uma situação de opressão e repressão racial em que o sujeito é "descartado como ator e protagonista em seu próprio mundo", a concepção de agência sugere (i) a reorientação da análise e da escrita, rumo à (ii) superação crítica da corrente anomia, economia de imagens e branqueamento, bem como à (iii) valorização das subjetividades e, por isso mesmo, das contradições e ambiguidades constitutivas das trajetórias e identidades sobre as quais os indivíduos assentam sua existência.

Nesse sentido, a busca pela agência tem por objetivo contribuir não só com a ampliação das consciências acerca das opressões e invisibilidades a que os negros são submetidos, mas trazer à superfície as insurgências crítico-humanísticas resultantes das diferentes expressões de resistência e resiliência historicamente protagonizadas pelo povo negro ao longo dos séculos e em todo o lugar. Tais considerações, em suma, visam reorientar as observações e escritas sobre o passado e presente, sobre os fenômenos socioculturais e biografias neles envolvidas.

Esse exercício de análise compreende quatro grandes tarefas, a saber: o estabelecimento da (i) localização psicossocial e histórica do sujeito, ou seja, a forma como ele concebe a si mesmo e o mundo, como se relaciona com as dimensões subjetivas e condicionantes externos de sua posição, deslocamento e identidade étnico-racial; (ii) dos elementos culturais africanos manifestos nos valores, memórias, linguagem e corporeidade; (iii) do refinamento léxico das palavras e sentidos que o sujeito busca exprimir quando narra a si mesmo e as próprias experiências e, por fim, (iv) de uma nova narrativa histórica capaz de expressar do sujeito sua complexidade, profundidade e irredutibilidade (Asante, 2009). Passamos agora à análise da narrativa biográfica da judoca Soraia André, reiterando que o uso de seu nome, bem como de todas as informações que se seguem, foi expressamente autorizado pela própria atleta.

\section{ANÁLISE}

\section{Soraia e a condição Olímpica, um universo de significados}

Soraia André nasceu na Zona Norte de São Paulo, no bairro da Casa Verde, em nove de agosto de 1964. Filha de Israel Laércio André e dona Neide de Jesus, irmã de mais quatro. Seu Israel ganhava a vida como auxiliar de mecânico e feirante, enquanto dona Neide trabalhava como empregada doméstica. Soraia inicia sua narrativa lembrando das privações pelas quais passou com a família e da falta de perspectivas de futuro que assombrava seus primeiros passos e desejos de ser. Antes de conhecer o esporte, gostava de fazer rima e poesia, a ponto de pedir ao pai que the comprasse um gravador, com o qual pudesse ensaiar seus primeiros versos. Mas seu Israel parecia ter planos um pouco diferentes para a aspirante à poetisa. Grande 
admirador dos esportes e pugilista dos tempos de Éder Jofre, procurou transmitir à filha o mesmo gosto pelo movimento, apresentando-a não à nobre arte, mas ao judô.

A partir desse momento, a trajetória da então adolescente Soraia passa a ser atravessada por questões socioculturais profundamente complexas, cujo enfrentamento só é possível mediante boas doses de encantamento e inconsequência, próprios da idade (Farias, 2012, p. 223; Rubio, 2015). Ao recordar 0 passado, a judoca tenta não só reconstituir os aspectos que compunham o referido cenário, mas atribuir traduzir os significados de sua participação nele.

Comecei a fazer judô em 1976, na academia Associação Judô Imirim, no bairro do Imirim, com o professor Koki Kanda. E foi aí que a gente começou. Só tinha homens no tatame, né. Uma que era [o judô] um esporte tradicionalmente masculino. Tinha até aquela lei ou decreto, não sei o número, que dizia ser proibido a prática. E na academia tinha doze mulheres. A prima de um professor, a irmã de um aluno, que praticavam de modo bem informal. Então chega a Soraia nessa Associação, bem diferente, bem tradicional, todos japoneses, os quais me perguntam: "você quer fazer o quê?" Quero aprender judô, respondi. Lógico que num primeiro momento não foi muito aquele "pode vir", porque eu estava entrando numa cultura que não era a minha, e eu, muito diferente de todo mundo, tive que fazer umas transformações em mim mesma. Tive até um apelido, "japonegra". Foi assim que minha história começou assim.

Em tese de doutorado que aborda a trajetória da referida atleta, Farias (2012, p. 223) demonstra que este não foi o primeiro encontro de Soraia com sua condição de mulher negra e periférica. Conta a autora que após ter concluído o ensino fundamental, Soraia ingressara em um curso de técnica em eletrônica. Ciente de que aquilo não a levaria à lugar algum, a jovem que hoje, ironicamente, diz "não saber trocar uma lâmpada", encarou aquela empreitada como um "desafio", tamanho o descontentamento com a situação da mulher à época e o compreensivo gosto pelo enfrentamento às interdições, "principalmente quando falavam ser proibido para as mulheres", diz. Numa turma em que não havia mais que três mulheres, conquistar 0 diploma era para Soraia uma questão de honra. Tarefa que não deixou por concluir, ciente que não seriam as interdições a impedi-la de aprender e conquistar algo. E que fique registrado: a primeira judoca olímpica afro-brasileira, também é técnica em eletrônica.

A "segunda" vez em que Soraia as fronteiras socioculturais de seu tempo compreendeu não só o encontro com expressões categóricas de hierarquias de gênero. Integrada à naturalização da invisibilidade e exclusão feminina do esporte estava a questão da "raça", que no campo das relações de poder, como é de conhecimento, sempre elegeu a brancura como expressão étnica mais legítima (Fernandes, 1972; Azevedo, 1982). Conforme a própria atleta remonta, o ingresso no judô representou para ela o encontro com uma cultura étnica e com códigos a partir dos quais sua condição de mulher e negra foi reafirmada, não só como marca da diferença, mas de desigualdade, uma vez que, para integrar-se ao grupo, precisou "embranquecer". Soma-se a isso o fato de que até meados dos anos 1970 não só judô como outras artes marciais e modalidades esportivas eram oficialmente proibidas às mulheres (Castellani Filho, 1989), restando a elas a experiência esportiva informal e a clandestinidade quando da subversão à regra. Embora Soraia contasse com o apoio incondicional do pai, e não tenha relatado qualquer interdição da Associação à sua participação, enfrentava oposição por parte da mãe, que não via com bons olhos a relação mulher $\mathrm{e}$ lutas. Para uma pessoa cujas interdições externas não significavam necessariamente impeditivos, encontrar na própria mãe a "voz da lei" representava um grande dilema, o qual a narradora assim interpreta: 
Meu pai era pura empolgação. Já minha mãe, nem tanto. Ela achava o que a lei também achava: que a mulher ia ficar masculinizada. Nesse ponto, os "doutores da lei" não se diferenciavam da incompreensão da minha mãe, uma vez que partilhavam da mesma opinião. Então, na verdade, a minha mãe também era uma "doutora da lei". Ela foi a minha primeira adversária, porque não queria que eu fizesse [judô]. Tive que travar uma luta ali: "vou, não vou, vou, não vou", de brigar. "Você vai virar homem, você vai virar homem", dizia ela, enquanto eu dizia que não, não iria. Acho que aí foi a minha maior motivação na verdade. Porque eu não sabia o que era judô, e a minha motivação foi "você vai virar homem", então eu quis pagar pra ver.

\section{A "nipo-negritude": Soraia entre identidades e ressignificações}

A atleta recorda que, à princípio, sua integração à comunidade judoística não foi simples, uma vez que "aquela não era minha cultura", condição que o próprio grupo ao qual ela se apresentou fez questão de reforçar, apelidando-a de "japonegra". Esse episódio, hoje lembrado com ironia, guarda questões históricas e culturais profundas, as quais, de acordo com Hall (2003), não se resumem à afirmação de poder, uma vez que envolve certo grau de "abertura" por parte de uma conformação e grupo étnico que, como Soraia, também se caracteriza como diaspórico e, por isso mesmo, sujeito aos "afrouxamentos" e processos de transculturação. Embora tenha sido externamente marcada pela sua condição de mulher e negra e sofrido o peso de carregar as representações negativas de tais atributos, Soraia não só progressivamente se inseriu como foi participante ativa de um processo de hibridização necessário aos fins de sua trajetória dentro do esporte.

Por esta ótica, a integração da atleta à comunidade judoística, representou muito mais uma afirmação de diferenças do que de desigualdade. Pois ainda que o codinome pudesse indicar haver um racismo não-dito, Soraia continuou ganhando espaço, muito em função do seu ímpeto subversivo, mas também da assimilação dos símbolos que caracterizavam a cultura que ela, progressivamente, diz ter aprendido a apreciar, tornando-a parte da própria identidade. Por duas razões, esse processo também significou 0 encontro da atleta com sua negritude negada, condição que a colocou diante de uma dupla tarefa: o já mencionado processo de assimilação simbólica da cultura nipônica, seguido da ressignificação particular de um ser negra.

Tive que fazer uns transformismos, se este for o termo correto. Eu alisava o cabelo, por isso que tinha o apelido de japonegra. Então foi muito difícil. Tudo que é do negro, na nossa cultura, é que não presta. Até o samba não presta. Eu tive que desaprender. Era o ritual do esqueça mesmo o que você é e adentre a nossa cultura. E não só do japonês, eu falo do preconceito mais instaurado, algo mais social. É difícil, porque você fica sem referência. Então, quando fui cortada, fui pro divã. Tive que me olhar no espelho e me deparar com uma pessoa que eu tinha esquecido quem era. E eu vi: meu nariz é ondulado, tenho um beição, tenho cabelo duro. E aí ter que responder pra si mesma quem é essa pessoa... Eu era japonegra, mas sou negra, e não sou mais a japonegra. É a figura, acabada. Isso é muito difícil. Difícil porque você tem que negar sua cultura, tem que negar seus valores. E eu só fui quem eu fui no judô, só aprendi, porque é muita ginga. Essa malemolência me ajudou e muito no judô. Talvez, se eu não tivesse isso da minha cultura, talvez eu não conseguisse fazer essa associação muito rápida, muito, muito solta.

Mbembe (2017, p. 255-256), na obra Crítica da razão negra, analisa em profundidade o substantivo negro, à princípio recorrendo à construção colonial do termo e à forma como esse construto circula no campo da 
linguagem e das identidades. Para o autor, "negro é, antes de mais, uma palavra", que por sua vez remete a um ou uma centena de significados, o que lhe dá "espessura e densidade próprias". Sua expressão tem por objetivo transmitir à consciência daquele a quem a palavra é atribuída, um conjunto de significados. Quanto mais significante for a palavra, mais sensações ela provoca. A ofensa, nesse sentido, será um dentro os elementos que conferem "peso" à palavra. Para uma perspectiva colonial e essencialista de mundo, "negro" será a palavra certa para a designação de um "suposto ser", cujo destino irreversível não será o mesmo dos não-negros. Em última análise, negro é um nome que foi dado por alguém à alguém. A pessoa que o recebe, não o escolheu originalmente, apenas o herdou como marca da posição geográfica e simbólica que ocupo no mundo. Contudo, "aquele que está marcado com o nome negro não se deixa enganar por esta providência externa”. É aí que se encontram os espaços de ressignificação.

Dentre os irmãos, Soraia foi a única que deu continuidade à prática esportiva. As condições desfavoráveis à prática, segundo aponta Farias (2012), em larga medida era o que impulsionava a atleta a conhecer para melhor lidar com as relações de poder e fatalismos que a sociedade reservada às pessoas da sua cor. Anonimamente, e à própria maneira, Soraia resistiu com "ginga e malemolência", mesmas qualidades que permitiu a muitos dos seus ancestrais e contemporâneos negros resistir ao etnocídio colonial, ao autoritarismo e políticas de branqueamento (Nascimento, 2003).

O caso de Soraia remonta uma história marcada tanto pelo encontro como pela defesa de uma negritude que, se não se fazia perceber legítima nas representações externas, confirmava-se inevitavelmente num rosto africano todo seu e de mais ninguém. Rosto que, a despeito dos "transformismos" pelos quais passou ao longo de sua passagem pela Associação de Judô, remetia-a a um lugar, a uma cultura, a uma história, uma raiz. Em entrevista cedida à pesquisadora Claudia Maria Farias (Farias, 2012, p. 224), a judoca reitera difícil processo pelo qual passou, e reconstitui o trabalho de ressignificação da identidade que teve de realizar:

... tive um preço muito alto a pagar, porque eu tinha que ter comportamentos ditos normais. Não podia gostar de samba, não podia ter meu cabelo ao natural, então foi um preço muito alto, mas eu vi que era uma luz; eu tinha certeza muito grande que através daquilo ia conseguir sair da margem e ter acesso pelo menos à educação, à cultura. Foi um preço que acabei pagando. Imagina você estar num lugar e as pessoas começarem a olhar para o seu cabelo e comentar alguma coisa, a querer tocar seu cabelo como se você fosse um bicho ou uma pessoa estranha? Ficava mais parecida com o tipo que queriam que eu fosse. No começo eu era negona, depois passei a ser neguinha, mulata e de cor. Então, a sociedade acabou me embranquecendo. Ou você é branca e faz judô ou se for negra, não tem acesso... Então, eu tive que aprender. Eu falava japonês, tinha que me comportar como uma gueixa. Meu apelido era 'japonegra', e até gosto. Eu gostava muito disso, me custou alguns anos de terapia depois, mas isso é outro capítulo que você não deve me perguntar. Então, era um significado mesmo, uma luz no fim do túnel, você abraça isso e ponto final!".

Viver sob um paradigma colonial da condição negra é inevitavelmente sofrer seus efeitos deletérios, muito embora também seja esta a condição das insurgências revolucionárias (Fanon, 2008). Em Mbembe (2017, p. 257-258) entendemos que ser negro implica estar, em grande medida, sob os parâmetros de significação do "outro", que, orientado a partir de uma razão racionalizante, por regra ocidental e essencialista, vê e interpreta "raça" e cor negras como marcas de uma não-humanidade ou de uma humanidade a ser forjada à luz da branquitude. Entretanto, em termos objetivos, não há cor e traços físicos que carregam um sentido em si mesmos. Mas se o sentido pode existir "por referência a um poder que o inventa", o mesmo pode se 
dar a partir de representações mais favoráveis ao grupo ao qual pertence determinada cor e traços. Soraia sugere que esse processo de ressignificação foi se constituindo gradativamente, e não sem apoio.

Conforme Farias (2012) analisa, as ambiguidades e deslocamentos temporais constitutivos da narrativa de Soraia indicam a forma como a atleta constrói, no presente, a própria memória e dá sentido à própria história. Suas lembranças se misturam à reflexões sobre os problemas e questões que enfrentou durante a prática do judô, ao mesmo tempo que denunciam o papel crucial do suporte terapêutico para 0 seu autoconhecimento. Processo o qual também influenciou sua transição de carreira, conforme se analisará mais à frente.

Nesta leitura sobre o passado a partir do presente, a atleta reinterpreta sua imersão na comunidade judoística identificando o paradoxo da vida entre identidades, o enfrentamento do racismo e das relações de poder, bem como a necessidade de "apropriação" dos elementos culturais que the eram disponíveis, de maneira que pudesse dar prosseguimento ao seu projeto emancipatório inadiável. Tal como ensina a arte do judô, Soraia usou da força dos seus concorrentes a seu próprio favor.

Fui gostando do assunto. A filosofia do judô é muito bonita. O progresso e a prosperidade de todos, muito diferente da nossa cultura. Junto com o esporte vem uma cultura muito rica, muito bonita, não só de filosofia de vida, mas algo de pessoal mesmo, de você aprender a cair, levantar, independente de onde você cai. E além do mais, judô significa caminho suave. Pra mim, era muito parecido com dança, então, estava muito próximo do gravador, da música, da arte, do quê eu queria fazer de fato.

\section{Soraia entre a condição Olímpica e a reivindicação da condição humana}

A história da inserção dos afro-brasileiros no esporte é por natureza paradoxal. Estrutura-se a partir de avanços e recuos muito pouco compreendidos, principalmente se o fenômeno é observado de um ponto de vista institucional e oficial da história, mais atento aos números e conquistas que aos enredos que levam a tais resultados, bem como às memórias e saberes dos "vencidos".

A dificuldade era assim: o que elas estão fazendo aqui nesse espaço que é nosso? Já começava por aí. Então, mulheres treinam pra cá e homens treinam pra lá. $E$ aí quando permitiram treinamento misto, ora os homens arrebentavam a gente, ora faziam corpo mole. Nunca faziam uma luta de igual pra igual. Então, havia aquele preconceito dentro da própria modalidade, né. E era assim: tem verba pra levar dois, leva-se dois homens, não um homem e uma mulher. Ou então: se ela tem um título Pan-Americano e ele tem um título Brasileiro, investe-se no homem. Ou seja, ser mulher no esporte é ser mulher na sociedade, não tem diferença nenhuma. E ser mulher num esporte masculino, é pior ainda.

Você é mulher. É mulher e negra. É mulher, negra e pobre. Só que aí a sociedade não te chama de negra, com aquele destaque. Eu era negra, negrona quando consegui entrar naquele tatame. Queria ser negrona. Com o passar do tempo, a nossa amiga morena [referindo-se a si mesma], virou "de cor". Peraí, não posso falar mais negona, pois sou uma atleta olímpica. $E$ como uma atleta olímpica negona? Não pode! É "de cor"... Falo isso com muita tranquilidade. Trabalho isso bem trabalhado, dentro de mim. 
Ferreira Junior (2019) localiza a trajetória esportiva dos afro-brasileiros em quatro momentos históricos, três dos quais se referem especificamente à experiência de Soraia. O primeiro, refere a um processo de exclusão deliberada não só dos negros, pautada em perspectivas científicas, crenças e políticas eugenistas, bem como em hierarquias de classe legitimadoras de posturas e afirmações contrárias à presença não só dos negros, mas dos mestiços e brancos pobres nos espaços então reservados à burguesia e aos brancos. 0 segundo aspecto se refere ao declínio das políticas eugenistas e do pessimismo racial, seguido da ascensão da apologia à mestiçagem e à integração (subordinada) dos negros à sociedade; processo marcado pela manutenção cordial e velada das velhas hierarquias, por sua vez ancoradas à ideia de que no Brasil prospera o convívio fraterno entre as "raças", bem como na supervalorização do negro para o desempenho de determinados papéis e tarefas relacionadas ao esforço físico. 0 terceiro e último aspecto refere-se a um período marcado pela resposta do conservadorismo racial aos processos de criminalização e desmoralização pública do racismo; momento em que o acervo de linguagens e expressões de cunho racial passa a ser substituído por relações "politicamente corretas", sem com isso tocar as relações de poder e hierarquias sociais baseadas na cor e classe dos indivíduos. Soraia construiu sua carreira atlética no interior desses processos, e, de maneira especialmente singular, demonstra não só como cada um destes aspectos atravessou seu caminho, mas como os encarou.

Sua fala nos sugere que os princípios e valores da modalidade desempenharam papel fundamental em seus processos de enfrentamento. A semelhança que a arte marcial estabelecia com a dança, conforme ela relata, indica que a atleta encontrava, mesmo em seu "não-lugar", aspectos que a mantinham próxima às coisas que lhe eram caras e mais familiares, tais como "a música, a arte, o quê eu queria fazer de fato".

O trabalho e perseverança da jovem judoca seria recompensada ao final dos anos 1970, quando da queda da lei que então proibia as mulheres de praticar artes marciais e outros esportes em alto rendimento. Em 1980, Soraia sagrou-se a primeira campeã estadual e brasileira de sua categoria. Títulos que viria a conquistar novamente nos anos seguintes. Em 1983, participou da primeira de suas três edições de Jogos Pan-Americanos (Caracas, Indianápolis e Havana), das quais retornou com duas medalhas de bronze e uma de ouro. Restava-lhe apenas a participação em Jogos Olímpico, a qual não tardaria a acontecer. Contudo, os significados dessa experiência e processo que fizeram de Soraia a primeira judoca afrobrasileira olímpica ultrapassam em muito a própria memória de sua breve passagem por Seul em 1988.

Fomos à primeira Olimpíada, que a bem da verdade, foi bem legal também. É um sonho realizado estar ali, principalmente depois de ter passado por uma história de proibição. O Brasil foi representado por duas judocas, Mônica e eu. Mas veja só, não houve uma preparação psicológica, física, embora hoje esta seja uma necessidade indispensável. Mas a preparação psicológica, na minha época, não existia. Na verdade, a gente vinha tendo esse treinamento com o passar das competições. Eu já tinha ido ao Mundial. À dois Mundiais, na verdade. E lá eu já tinha visto coisas que eu nunca tinha visto aqui, quando aqui ainda era proibido. Chego ao mundial e vejo aquele nível das europeias, das americanas, então, de certo modo a vida estava nos preparando. Mas não era um trabalho focado como eu sei que hoje a Confederação Brasileira faz, com psicólogo, preparador físico. Então, a gente não estava preparada para uma Olimpíada, pra saber o que é uma Olimpíada. Eu acho que esse preparo emocional é fundamental.

Fiz a minha primeira luta com a campeã olímpica. Ou eu ganharia ou teria que disputar repescagem. E foi o quê aconteceu. Perdi, mas ela [adversária] foi caminhando na chave e me puxou pra repescagem. Fui enfrentar uma japonesa. Eu estava ganhando a luta, mas não 
estava preparada pra ganhar, menos ainda pra ser medalhista. Hoje, revivendo a emoção e fazendo um balanço de tudo, recordo que perdi a luta faltando 47 segundos. Então, não foi a falta de preparo técnico, e sim de preparo para ser uma atleta, medalhista, olímpica.

O fim da proibição à prática esportiva em alto rendimento para as mulheres não representou mudança significativas na mentalidade das organizações esportivas. Os frutos desse período de rupturas, marcado por lutas anti-regime ditatorial e pela democracia constitucional, só viriam muito mais tarde, mas não contemplariam Soraia e suas contemporâneas. 0 esporte olímpico brasileiro de um modo geral, embora disputado em alto rendimento desde a sua gênese, permaneceria amador.

Com base nas memórias do seu intercâmbio cultural esportivo, Soraia retoma esse assunto, reforçando a necessidade de preparação do atleta, entendendo que esse processo não deveria se restringir à preparação competitiva, uma vez que a condição olímpica implica tanto questões emocionais como sociais. "Pois ali quando você coloca o agasalho escrito Brasil, não é você, mas o país todo, uma nação". A complexidade da condição olímpica, segundo Soraia, transcende o tempo espaço competitivo, pois insere o atleta numa dimensão geopolítica da qual ele geralmente não está apercebido. Ela conta que os contrastes culturais expressos na organização e infra-estrutura, bem como o encontro entre culturas nacionais distintas fez com que ela se apercebesse de uma série de estereótipos que os estrangeiros que os estrangeiros atribuíam ao Brasil e aos Brasileiros. "Quando nós chegávamos e falávamos que éramos brasileiras, as pessoas não davam a mão pra cumprimentar, queriam passar a mão, pois era isso que se sabe de Brasil", recorda a atleta quando em Seul. Exaustivamente investigada por renomados intelectuais, a identidade brasileira, conforme sugere Souza (2017), foi - como continua a ser - equivocadamente associada à pressupostos implicitamente racistas que reduzem o brasileiro à uma dada sexualidade, corporeidade, cordialidade, emotividade que impediria ou que não estabelece relação com a razão. 0 ter experimentado na própria pele tais contradições, permitiu com que Soraia leva-se de suas vivências esportivas internacionais uma compreensão mais planetária sobre o lugar que ocupa não só na sociedade a que pertence, mas no mundo.

A judoca voltaria à cena olímpica quatro anos mais tarde para participar dos Jogos de Barcelona, mas a derrota na primeira rodada a eliminaria precocemente do torneio. Esse período de sua trajetória foi marcado por conflitos de ordem política que, segundo a atleta, teria determinado seu desligamento da seleção brasileira de judô, da qual fazia parte há mais de dez anos. Em 1993, quando voltava de competição, recebeu notícia de que havia sido cortada da equipe. A isso, atribui o fato de que, um ano antes, por suspeitar do mal uso das verbas destinadas à modalidade, viu-se na responsabilidade de exigir explicações dos dirigentes. Entretanto, reivindicações do tipo pareciam não combinar com o silêncio e resignação estruturantes do modelo autocrático e pouco transparente da Confederação à época, que em janeiro dispensou Soraia. A judoca lembra ainda que foi no mesmo ano a instituição mudou as regras de participação das atletas nas seletivas, reduzindo a idade limite das postulantes para 28 anos. À época, Soraia tinha 29.

Foi onde eu fiz meu protesto. Pintei meu quimono de preto. Foi meu luto. Ali vivi meu luto mesmo. E falava: eles me mataram, de verdade, agora eles conseguiram! Deixei meu quimoninho todo de preto e fui para uma seletiva do Rio de Janeiro. Fiz um protesto calada. Mas eu acho que quando você cala e faz o protesto, outras feridas se abrem. Durante meu protesto silencioso, ouvia "agora é que ela não vai mesmo. Ela tá de preto". Mas fiz com o intuito de chocar. E foi muito legal isso. 
Os últimos anos da carreira atlética de Soraia falam de um período de radicalização política e luta contra resignações e silêncios, principalmente quanto à gestão da entidade confederativa e a falta de reconhecimento aos atletas. A superação das interdições do passado, somado aos intercâmbios de conscientização culturais teriam feito da judoca uma lutadora para além dos tatames, reivindicadora, mas ao mesmo tempo ciente de que não tinha força suficiente para derrotar os adversários contra os quais passou a lutar, e de que precisaria guardar energia para lidar com o término da carreira.

Soraia havia encontrado no judô não só uma paixão, mas uma plataforma de emancipação social. Razões em nome das quais dedicou toda a juventude. Apesar de todo aprendizado adquirido, não pôde escapar às dúvidas e angústias acerca do que iria encontrar na vida pós-atleta. "Parei de competir. No entanto, só sabia fazer isso [judô], não sei fazer outra coisa. Foi então que veio todo trabalho interno, comigo mesma. Tinha as coisas de divã, e tinha as coisas de Deus". Soraia, como a grande maioria dos atletas que perseguem 0 sonho olímpico, não teve a chance de passar por um processo de preparação para o término da carreira atlética. Mais sorte têm os que vivenciam a carreira atlética estabelecendo trânsito entre a vida esportiva e cotidiana (Ferreira Junior \& Rubio, 2017). O término da carreira atlética é uma fase inevitável da vida esportiva. Implica um processo de transição complexo, não linear e muito particular, que envolve a ressignificação não só da identidade laboral, mas social, desafiando o pós-atleta à construção de outras formas de ser e estar no mundo. Para lidar com isso, Soraia contou com suporte psicológico. Experiência a qual elabora da seguinte forma:

Foi um processo intenso. No divã eu buscava me entender, responder pra mim mesmo o "e depois?"... Doei todas as minhas medalhas. Elas estão todas no museu de Santo André. Até isso eu fiz, pra desconstruir aquilo que eu vivia. A doação foi em duas etapas, 2005 e 2006. Então, foi um desconstruir pra poder "peraí, acabou mesmo". Mas aí a gente começa a ser de verdade. Fiquei parceira de um projeto chamado Caravana do Esporte, que utiliza o esporte como ferramenta de inclusão para os Estados onde as pessoas não tem nem o que comer, tampouco com o que sonhar. Então eu tive de passar por um processo de desconstrução. Jogar tudo fora, que não é nem jogar. Sou cristã, sempre oro e peço a Deus uma direção. E eu briguei com Deus naquele dia. Eu falei "Deus, peraí. Como? Agora eu tenho um monte de medalha, de troféu e vou jogar tudo fora? Eu quero uma estratégia". E eu dormi e acordei com uma estratégia: "liga pro museu de Santo André e vê se querem.

\section{CONSIDERAÇÕES FINAIS}

Formada em psicologia, a hoje Sensei Soraia trabalha com iniciação esportiva em Santo André. Também atua na preparação psicológica de judocas de alta performance e presta atendimento psicológico em clínica particular. Sua experiência de transição de carreira parece ter se traduzido numa síntese daquilo que vivenciou no esporte, por meio do qual buscou escapar ao prognóstico pessimista de uma infância cheia de privações.

Por meio de suas memórias e narrativa é possível entender que o processo de inserção e participação no esporte transcende as questões de ordem técnica, demandando dos seus aspirantes conhecimentos e sensibilidade acerca das identidades, bem como das estruturas de poder constitutivas da cultura esportiva e das modalidades. Do judô, Soraia extrai uma experiência plena em ambiguidades, uma vez que implicou tanto o seu processo de "embranquecimento", quanto de emancipação e formação política. Posto isso, não surpreende o fato de a atleta ter transformada a sua experiência esportiva num pólo de resistência aos reducionismos que uma época marcada por ditadura e interdições impunha às mulheres, principalmente 
àquelas que, como Soraia, tinham que lidar com representações negativas atribuídas a cor e etnia negra. À própria maneira, Soraia evoca a sua negritude através dos traços que, mesmo negados e deslegitimados pela cultura judoística, falavam de um corpo, passado e cultura que também Ihe pertencia e cuja importância não se compara. Os fragmentos dessa reminiscência, segundo ela mesma recorda, foram encontrados nas bases da própria cultura da modalidade que aprendeu, "não-lugar" onde a judoca, estrategicamente, assume uma forma híbrida, através da qual vai perseguir seus interesses esportivos.

Por fim, sua trajetória sugere que a formação do atleta - diferentemente do pressuposto da alienação compreende a tomada de consciência constante sobre as já mencionadas relações de poder, as quais cotidianamente convocando o protagonista esportivo à defesa de sua condição humana, legitimidade social e laboral. Mais estudo sobre esse tema e suas variáveis são necessárias, principalmente no que se refere à participação e protagonismo das mulheres negras no e através do esporte. Nesse caso em específico, as abordagens pós-colonial e afrocentrada apresentam-se como aportes teóricos que conferem especial valor e tratamento às biografias e narrativas dos sujeitos históricos em foco.

\section{REFERÊNCIAS}

Abrahão, B. O. L., Soares, A. J. G. (2012). A imprensa negra e o futebol em São Paulo no início do século XX. Revista Brasileira de Educação Física. Esporte, São Paulo, 26(1): 63-76. https://doi.org/10.1590/s1807-55092012000100007

Asante, M. K. (2009). Afrocentricidade: notas sobre uma posição disciplinar. In: Nascimento, E. L. (Org.) Afrocentricidade: uma abordagem epistemológica inovadora. São Paulo: Selo Negro, 93-110.

Azevedo, C. M. (1987). Onda negra, medo branco: imaginário das elites - século XIX. Rio de Janeiro: Paz e Terra.

Castellani Filho, L. (1989). Esporte e mulher. Revista Motrivivência, (2): 87-92.

Domingues, P. (2009). Fios de Ariadne: o protagonismo negro no pós-abolição. Anos 90, Porto Alegre, 16(30): 215-250.

Dussel, E. D. (1977). Filosofia da Libertação na América Latina. São Paulo: Loyola.

Farias, C. M. (2011). Superando barreiras e preconceitos: trajetórias, narrativas e memórias de atletas negras. Revista Estudos Feministas. 19(3): 911-929. https://doi.org/10.1590/s0104$\underline{026 \times 2011000300014}$

Farias, C. M. (2012). Sonhos, lutas e conquistas: projeção e emancipação social das mulheres nos esportes, 1932-1979. Tese (Doutorado) - Universidade Federal Fluminense, Instituto de Ciências Humanas e Filosofia, Departamento de História.

Fernandes, F. (1972). O negro no mundo dos brancos. São Paulo: Difusão Europeia do Livro.

Freitas Junior, M. A.; Ribeiro, L. C. (2012). Vitórias e derrotas de um futebol mestiço: reflexões sobre a questão racial no Brasil. Emancipação, Ponta Grossa, 12(2): 297-309. https://doi.org/10.5212/emancipacao.v.12i2.0010

Ferreira Junior, N. S., Rubio, K. (2017). Retirement, transition and post-athlete life between Brazilian Olympic corridors. Olimpianos - Journal of Olympic Studies, 1(2): 187-209. https://doi.org/10.30937/2526-6314.v1n2.id22

Gilroy, P. (2007). Entre campos: nações, cultura e o fascínio da raça. São Paulo: Annablume.

Goellner. S. V. (2007). Feminismos, mulheres e esportes: questões epistemológicas sobre o fazer historiográfico. Revista Movimento, Porto Alegre, 13(2): 171 - 196.

Hall, S. (2003). Da diáspora: identidade e mediações culturais. Belo Horizonte: Editora UFMG Representação da UNESCO no Brasil. 
Jesus, G. M. (1999). "O futebol da canela preta: o negro e a modernidade em Porto Alegre". Anos 90, Porto Alegre, 11, 144-161.

Mbembe, A. (2017). Crítica da razão negra. Lisboa: Antígona, 2 eds. https://doi.org/10.17231/comsoc.34(2018).2960

Nascimento, E. L. (2003). O sortilégio da cor. São Paulo: Selo Negro.

Nascimento, E. L. (2009). Afrocentricidade: uma abordagem epistemológica inovadora. São Paulo: Selo Negro.

Oglesby, C. (2017). Transformations in women's sport across time and cultural boundaries. Olimpianos Journal of Olympic Studies. 2017; 1(3): 247-256. https://doi.org/10.30937/2526-6314.v1n3.id32

Rigo, L. C.; Filho, M. (1996). O negro no football brasileiro - resenha. Revista Movimento, 3(4): 56-61.

Rubio, K. (2014). Memórias e narrativas biográficas de atletas olímpicos brasileiros. In: RUBIO, K. (Org.) Preservação da memória: a responsabilidade dos Jogos Olímpicos. São Paulo: Képos, 105-122. https://doi.org/10.11606/t.39.2019.tde-20022019-100804

Rubio, K. (2015). Atletas Olímpicos Brasileiros. São Paulo: SESI-SP Editora.

Santos, J. A. (2000). Os intelectuais e as críticas às práticas esportivas no Brasil (1890-1947). Dissertação (Mestrado em História Social) - Faculdade de Filosofia, Letras e Ciências Humanas, Universidade de São Paulo, São Paulo. https://doi.org/10.18676/cadernoscenpec.v3i1.208

Soares, A. J. (1999). Racismo no futebol do Rio de Janeiro nos anos 20: uma história de identidade. Revista Paulista de Educação Física. São Paulo, v. 13, n. 1, p. 119-29. https://doi.org/10.11606/issn.2594-5904.rpef.1999.139862

Rodrigues Filho, M. (2003). O negro no futebol brasileiro. Rio de Janeiro: Mauad.

Souza, J. (2017). A elite do atraso: da escravidão à Lava Jato / Jessé Souza. - Rio de Janeiro: Leya. https://doi.org/10.5380/nep.v4i1.60232

Wiggins, D. K. (2014). "Black athletes in white men's games": race, sport and American National Pastimes. The International Journal of History of Sport. 31(1-2): 181-202. https://doi.org/10.1080/09523367.2013.857313 